\title{
Papel de la Universidad Santo Tomás en la gesta independentista
}

\author{
Role of Santo Tomás University in \\ Independence
}

Fecha de recepción: 22 de agosto de 2010

Fecha de aprobación: 18 de noviembre de 2010

\begin{abstract}
Alberto Cárdenas Patiño*
\section{Resumen}

Breve historiovisión en torno al papel cumplido por la Universidad Santo Tomás en la gesta independentista, desde los esbozos ideológicos precursores hasta la supresión de 1826 en beneficio de la Universidad Central santanderista, y luego su gradual recuperación y fortalecimiento académico hasta la restauración de 1855. Se intenta discernir, con ocasión de la conmemoración del Bicentenario de la Independencia, qué lecciones podemos recibir aún de nuestra memoria institucional.
\end{abstract}

Palabras clave: pródromos, "Columbania", gesta independentista, la Tomística, "Cédula del Común", eutopía, prospección, humanismo cristiano tomista.

\section{Abstract}

This is a historical analysis of the role of the University of Santo Tomás played in the independence of our country, from the precursor ideas of Independence, until the suppression in 1826, which was beneficial to the Santander Central University, and then its gradual recovery and academic strengthening until the restoration of 1855. We try to show, on the occasion of the commemoration of the Bicentennial of Independence, what lessons can still be received from our institutional memory.

Key words: prodrome, "Columbania", Independece, Thomistic, "Certificate of the Common", eutopia, exploration, Thomistic Cristian humanism.

Miembro de la Sociedad Internacional Tomás de Aquino, ex secretario General, ex director de la Unidad de Planeación y Perfeccionamiento Docente, ex decano de la Facultad de Filosofía. Representante del Rector General ante el Consejo de la Facultad de Derecho de la Universidad Santo Tomás. Licenciado en Filosofía y Humanismo, licenciado en Filología e Idiomas, doctor en Derecho y Ciencias Sociales. Correo electrónico: torreondomingo@hotmail.com 


\section{PRÓDROMOS IDEOLÓGICOS}

Si la gesta independentista no comenzó como un acontecimiento inesperado y repentino el 20 de julio de 1810 , sino que fue el resultado de un prolongado proceso que ya se preparaba en el seno de la sociedad colonial, que afectó gradualmente a sus distintas instituciones rectoras, es preciso rememorar en la historia de cada una de estas, para tratar de comprender qué factores cambiaban de manera imperceptible sus correspondientes funciones sociales.

Es lo que intentaré, de entrada, examinando los énfasis ideológicos que venían transformando la mentalidad escolástica recibida y conservada por la Universidad Tomística del Nuevo Reino de Granada, mentalidad compartida por todo el aparato educativo neogranadino, especialmente si se tiene en cuenta el papel de coordinación y control académicos que aquella debió desempeñar durante sesenta años, el tiempo que mide los sucesos antecedentes al Grito de Independencia y los que echan las bases de la etapa que Nariño ${ }^{2}$ llamó Patria Boba (1810-1816), hasta alcanzar la consolidación de la Segunda República, hacia 1826, cuando el general Santander inaugura su nuevo proyecto universitario, que margina a la pionera Universidad de la Colonia neogranadina, poco dispuesta a renunciar a su autonomía (Plata, 2005, pp. 297 ss).

Al integrar sucesivos textos, temas y prácticas profesorales, de distintas épocas, descubrimos un "colegio invisible" que venía articulando un discurso innovador de sentido autonomista, con ingredientes de la tradición dominicano-tomista, resemantizados en cada nueva etapa, según las indicaciones de las cambiantes tendencias colectivas. El arranque de ese discurso transtemporal ya se insinuaba tímidamente a finales del siglo XVII con la historia del dominico tomasino santa-

2 “Los Toros de Fucha, Tercera Corrida" (1823). fereño, de origen payanés, fray Alonso de Zamora (Zamora, 1980, pp. 56 ss), fuente importante para la comprensión de la historia colombiana especialmente durante el siglo XVII. Zamora fue el primer historiador del Colegio-Universidad Santo Tomás y resaltó el papel del Arzobispo fray Cristóbal de Torres, tanto en la consolidación jurídica de la tomística en 1639 como en el origen del Colegio Mayor de Nuestra Señora del Rosario entre 1651 y 1653.

Zamora examina los primeros 200 años del proceso conquistador-colonizador del Nuevo Continente, lo que aprovecha para reclamar que América sea reconocida como un auténtico "mundo" frente a Asia, África y Europa; y que el Nuevo Reino de Granada sea identificado como "uno de los principales reinos de tierra firme". Pero fray Alonso -con asomos precoces, aunque inseguros, de crítica al eurocentrismo- no pierde de vista la América toda como gran nación continental, de la que son deudoras España, Portugal, Holanda, Francia, Inglaterra, en fin, toda Europa. Lamenta que América se llame América y no "Colona" o "Columbania", pues sólo el nombre de Colón "debía ilustrar tan gloriosa empresa" (Zamora, 1980, pp. 56 ss).

En ese contexto, su intención es relievar el paradigma misionero de los dominicos, caracterizado por asumir expresamente la necesidad de afrontar las prácticas depredadoras de conquistadores y encomenderos reivindicando la dignidad humana de los indios, fuente de derechos y libertades "comunes a todo el género humano" (Zamora, 1980, pp. 81 ss). Zamora recuerda las grandes figuras del afrontamiento dominicano: fray Pedro de Córdoba y fray Antón de Montesinos, que inician en 1511 la protesta por los abusos contra los indios; protesta continuada por el activismo contestatario e insobornable de fray Bartolomé de Las Casas, hasta alcanzar, en 1537, el reconocimiento de la humanidad indiana mediante la Bula "Sublimis Deus" de Paulo III, gracias a la presión directa de fray Domingo de Betanzos y del obispo fray Julián 
Garcés, quienes enviaron secretamente a Roma al eficiente y sagaz procurador fray Bernardino de Minaya.

Al constructo formado por las tesis de la identidad diferenciante de "Columbania" y de la principalía novogranatense, junto con la medular afirmación del humanismo liberador dominicano, se van agregando ingredientes doctrinales con renovado acento, principalmente desde la segunda mitad del siglo XVIII: por ejemplo, el del ejercicio de la libertad para que el hombre se convierta en agente autónomo, causa de sí mismo, condición para realizar la esencia humana, problema que preocupaba al profesor de teología moral fray Jacinto Antonio De Buenaventura en 1759 (De Buenaventura, 1984, pp. 190 ss), años antes de su actuación como procurador de la tomística contra el proyecto de suprimirla por parte del fiscal Moreno y Escandón, graduado de la misma Universidad; la doble tesis sobre la culpabilidad al tolerar la injusticia y, para precaverla, el deber de limitar el poder de los gobernantes, asuntos que interesaban, en 1762, al jusfilósofo y rector de la Tomística fray Antonio Cabrejo.

A las preocupaciones teóricas anteriores, es preciso añadir los debates de aula acerca de las doctrinas tomasianas sobre el "régimen mixto" como el mejor régimen político y sobre la resistencia al "tirano" y la posibilidad del "tiranicidio", doctrinas prohibidas por el rey en 1768. Una "memoria"3 profesoral de autor anónimo -sin duda, para evitar conflictos con la metrópoli- se apresuraba a responder de manera políticamente correcta a la exigencia real.

Se dieron también prácticas institucionales laxas frente a imperativos estatutarios, como en el caso de la exigencia de pureza de sangre y legitimidad, requisitos esenciales para graduarse. Lo declaraba expresamente el texto del diploma: "Honorabilis vir, purus ab omni macula sanguinis atque legitimis e natalibus descendens": "Varón honorable, puro de toda mancha de sangre y descendiente de padres legítimos" ${ }^{\prime \prime}$. Flexibilizar esas previsiones rígidas, excepcionando por epiqueya, se traducía en oportunidades de ascenso profesional y social para mestizos, mulatos y posiblemente para algunos indios o negros, con lo cual se venían afectando los privilegios excluyentes de los criollos. Por haber graduado en cánones y leyes al mulato cartagenero don Cristóbal Polo, el rey Carlos III había amonestado en 1765 al rector y al claustro de la Tomística. Y no fue un caso aislado. Desde el siglo XVII se dieron varios casos de "impuros" que habían optado grados, aun entre los religiosos dominicos, incluyendo al mismo fray Alonso de Zamora (Parra, 1980, p. 9), descendiente de Cacique.

\section{EL CAMBIO DE MENTALIDAD SE TRADUCE EN ACCIÓN POLÍTICA}

Se fue creando en los claustros tomasinos una atmósfera doctrinal y práctica que transmutaba la mentalidad académica y legitimaba innovaciones discursivas y cambios de actitud. Fue lo que propició, sin duda, que el hermano fray Ciriaco de Archila, originario de Simacota, portero del Convento de Santo Domingo y de la Universidad se fuera apropiando de cuanto se discutía en pasillos, aulas o salas de espera acerca de asuntos políticos, con lo cual se habilitó para componer la "Cédula del Común", 41 octavas y un cuarteto (Ariza, 1971), dirigidos a animar a sus paisanos los comuneros socorranos que marchaban hacia Santafé en 1781, originando un movimiento de masas de diferente composición étnica y social.

3 Memoria Justificativa de sentimientos del Angélico Doctor Santo Tomás sobre la absoluta independencia de los Soberanos, sobre la indisolubilidad del juramento de sus vasallos, y sobre el Regicidio, manuscrito anónimo, mediados del siglo XVIII, Archivo de la Provincia Dominicana de Colombia.

4 Archivo de provincia, Convento San Alberto Magno, diplomas Universidad Tomística. 
El 16 de marzo de 1781, día de mercado, se había revelado la Villa del Socorro a causa de los reajustes en impuestos sobre compraventas y permutas, según Decreto del Regente Gutiérrez de Piñeres, que afectaba especialmente a las poblaciones con mayor actividad comercial. El levantamiento se tornó vociferante y amenazante en apoyo a la vendedora de frutas Manuela Beltrán, que tomó la iniciativa de romper el Edicto impositivo.

A comienzos de abril del mismo año, el hermano Archila redactó los versos y entró en contacto con influyentes criollos santafereños que protestaban por las nuevas medidas fiscales, entre ellos el Marqués de San Jorge, don José Miguel Lozano de Peralta, graduado de la Tomística. Éste hizo imprimir las estrofas y se encargó de divulgarlas, de tal manera que los grupos comuneros que marchaban hacia Santafé las hicieron suyas.

La "Cédula del Común" del hermano Archila constituye todo un manifiesto de convocatoria política. Después de ironizar acerca del "socorro" impositivo a favor del Fisco, pasa a ponderar la rebelión del Socorro -en la que ve el "dedo de Dios"-, para destacar luego el protagonismo de una mujer capaz de superar la pusilanimidad de los varones, amansados como "borricos que no sienten las enjalmas". El Socorro, que no soporta tiranos, deberá venir a socorrer, pero no al "pícaro regente", a quien hay que acabar, sino a santa fe timorata. Pero ésta está obligada a ayudar a El Socorro, que no debe temer a los soldados, "pobres borriqueros". Hay que acabar con el fiscal Moreno y Escandón, "pirata condenado", que quiso destruir las instituciones eclesiásticas, especialmente las educativas, y ha perseguido a los indios, de quienes debía ser verdadero protector. A los indios se les debe "amor y compasión". Regente y fiscal están asociados para enriquecerse.

Quito y Popayán, seguidores de Tupac Amarú, son modelos a imitar. Es preciso rechazar a los gobernantes que vienen de fuera, como han hecho
México y Lima. "Unámonos, por Dios, si les parece, / y veamos el Reino a quién le pertenece. / Sólo nosotros estamos de pendejos, / en las Indias las vainas aguantando". (Ariza, 1971, p. 150). Archila anima de nuevo a El Socorro y le calcula dos meses para llegar a Santafé. Los socorranos no deben tomar en serio al jefe militar Campuzano, que es un cobarde y será atajado por los tunjanos. No se debe creer a los frailes capuchinos, quienes intentan persuadir al pueblo de que es pecado mortal luchar por un derecho natural, y de que "es muy justo que os roben la camisa". Y en el cuarteto de cierre, Archila advierte al Regente que no le valdrá duplicar la guardia (Ariza, 1971, p. 150) .

La "Cédula del Común" se llamaba así en contraposición a la "Cédula Real", dando a entender que así como ésta era un mandato, también la primera lo era, pero del pueblo, del "común" sin discriminación, fuente de la soberanía. Asertos claves que estructuran las estrofas del Hermano Archila: a) resistir a la tiranía es voluntad de Dios $y$ un derecho natural; $b$ ) a los indios se les debe protección; c) los dominios americanos tienen sus propios dueños que pueden gobernarse a sí mismos; d) la unión es la fuerza decisiva contra la opresión; e) hay que contar con la capacidad de lucha de la mujer.

La revuelta social comunera iluminará el camino a la casta criolla, que va a intentar un cambio políticoadministrativo. Durante 30 años el comunerismo sirve de estímulo a los tomistas, que recuerdan especialmente los reclamos del hermano Archila.

\section{LA TOMÍSTICA: ÚNICA UNIVERSIDAD DEL NUEVO REINO DE GRANADA}

Tras la desaparición de la Javeriana, en 1767, el Colegio-Universidad Santo Tomás quedó no sólo con sus propios estudios aprobados a perpetuidad y con derecho a establecer cátedras de todas las

5 "Cédula del Común". 
facultades aceptadas en la Legislación de Indias, sino como central única de exámenes y grados para todas las demás instituciones de educación superior del Virreinato: Colegio Mayor de Nuestra Señora del Rosario -al que se consideraba incorporado a la Universidad Tomística-, Colegio de San Bartolomé -elevado a Mayor en 1779-, Colegio de San Buenaventura, Colegio de San Nicolás, Estudios dominicanos de Tunja, Cartagena, Santa Marta y Popayán, y de varios seminarios diocesanos, etc. A todo ello, la Universidad agregaba estudios preuniversitarios y escuela de primeras letras, puerta de entrada a todo el sistema educativo, en la que era posible el encuentro de las distintas clases sociales.

Durante el tiempo en que Tomística y Javeriana emulaban por hacer lucir sus estudios y aumentar el número de sus estudiantes, la primera graduaba a sus propios colegiales y a los del Colegio Mayor de Nuestra Señora del Rosario, y la segunda a los suyos y a los del Colegio de San Bartolomé. Pero, aunque conocemos los nombres de muchos egresados, no contamos - a causa de la repetida pérdida de archivos-, ni con los libros de matrícula, ni con los libros de grado de los "tomistas" durante ese lapso. Afortunadamente, nos queda constancia precisa de cuantos se graduaron durante los cuarenta años siguientes al extrañamiento de la Compañía y al pleito con Moreno y Escandón. Se trata del "Libro de Propinas" de la Tomística, ordenado por el rector fray Antonio Cabrejo, en el cual constan 2281 grados entre 1768 y 1808: un promedio de 57 grados por año (Molina, 1984) ${ }^{6}$. Número de grados significativo para una Santafé estacionaria, con unos 30.000 habitantes, en un Virreinato despoblado con no más de millón y medio de personas.

En esos cuarenta años que cubre el "Libro de Propinas" - uno de los "Libros raros y curiosos"

6 “800 titulados en filosofía entre 1768-1808". En: Cuadernos de Filosofía Latinoamericana, 21. de la Biblioteca Nacional de Colombia, sala de seguridad 145-, el Colegio-Universidad confirió 1264 títulos de Bachiller, 390 de licenciado, 397 de doctor y 29 de maestro para un total de 1108 estudiantes, en alguna o hasta en cuatro de las facultades aprobadas: filosofía, teología, cánones, leyes, medicina. Los graduados procedían tanto de la Tomística como de los demás centros de educación superior del Virreinato.

No sabemos mucho acerca de los requisitos de grado. Por lo general, si se trataba de estudiantes propios, debían cursar hasta seis años, después del pre-universitario, para lograr el doctorado, seguidos de los exámenes o "tremendas" de cada etapa formativa o de las "conferencias" de culminación doctoral. Si se trataba de los estudios dominicanos mencionados, y con ellos el Colegio de Nuestra Señora del Rosario, por considerarse incorporados, allegada la certificación de terminación de estudios, sólo debían someterse a "tremendas" o a las "conferencias" de rigor. En cuanto a las demás instituciones, parece que sus estudiantes debían hacer en la Tomística cursos complementarios de filosofía, teología o cánones, antes de examinarse o sustentar.

\section{PAPEL DE LOS GRADUADOS DEL "LIBRO DE PROPINAS"}

Muchos graduados registrados en el "Libro de Propinas" - de distinta procedencia formativadesempeñarán papel importante en los cambios de la vida cultural y política neogranadina. Pero esa influencia será de distinto signo (frenadora, aceleradora o de ruptura), según el momento generacional en que se reciban los títulos. En general, los graduados más antiguos (del 67 al 77) influirán en función de mantenimiento y fieles a los planes borbónicos en la renovación ilustrada de las instituciones coloniales; los de la segunda generación (78 al 88), cuestionarán las relaciones metrópoli-Virreinato -reivindicando la tendencia al federalismo preborbónico- y propondrán modera- 
das formas de cambio en sentido autonomista; los de la tercera generación ( 89 al 99 ) tendrán muy presentes las ideas americanistas de los antiguos maestros de Salamanca y las ideas escolásticas sobre democracia, régimen mixto y tiranicidio -estructura intelectual de su formación política, que ayudará a asimilar la ideología de los antecedentes revolucionarios francés y norteamericano-, y mostrarán cierto radicalismo subversivo contra el centralismo borbónico; $y$ los de la postrera generación (1800-1808) ya serán, en plena juventud, los protagonistas de la Independencia y de la República. No obstante, graduados de distintas generaciones se encontrarán con los más jóvenes a la hora de tomar las armas o de contribuir, a veces por inercia, en la organización político-jurídica de la nueva República; y no siempre serán los graduados más antiguos los más conservadores.

Citemos algunos nombres muy conocidos: a) de la primera generación: José Ignacio de Rentería (teología y cánones), Manuel Antonio de Campo y Rivas (cánones y leyes), José Domingo Duquesne (cánones), Eloy Valenzuela (filosofía y teología), Fernando Caicedo (filosofía y teología), fray Santiago de Buenaventura (teología); b) de la segunda generación: Andrés Rosillo (filosofía, teología, cánones), Camilo Torres (teología y cánones), José Félix de Restrepo (filosofía, leyes); c) de la tercera generación: Francisco José de Caldas (cánones), José del Castillo y Rada (filosofía y leyes), José Maria Cabal (leyes); d) de la última generación: Vicente Azuero (teología), José María Estévez (filosofía, cánones, leyes), Elías López Tagle (filosofía, teología cánones), Joaquín Mosquera (filosofía, cánones), Francisco de Paula Santander (filosofía) (Cárdenas, Revista Realidad, No. 4, p 13).

\section{ACCIONES SUBVERSIVAS DE LOS "TOMISTAS"}

De la "Real Cédula" que, en enero de 1792, establecía en la ciudad de Granada un "Colegio de nobles americanos" se infiere que ya el rey no se fiaba de las universidades coloniales para la formación en las "carreras de mi real servicio". El monarca pensaba que sólo con una institución de educación superior bajo su control directo podría "certificarse" de su mérito "para emplearlos, así en España como en América". En el Colegio de Nobles Americanos se daría "la sólida y verdadera educación que corresponde al eclesiástico, al magistrado, al militar y al político" (Groot, 1953, p. 648).

Dos años después de esta "Real Cédula", cuanto ocurre en los claustros de la Tomística hubiera podido usarse para reforzar la íntima desconfianza del rey: entre 1794-1795, se tienen allí juntas secretas en pro de la "revolución" y discusiones acerca de la libertad "de que disfrutan los franceses" (Tisnés, 1971, p. 58). Además, por las noches se elaboran pasquines antigubernamentales en prosa y en verso, que amanecen fijados en sitios céntricos de Santafé. Y los "tomistas" del Rosario sin duda que acudían a citas clandestinas.

El tomismo era pensamiento oficial para asegurar la corrección ideológica de las instituciones que servían a la monarquía. Pero desde hacía décadas, los "tomistas" venían jugando a la subversión. En 1763 fue preciso sofocar a golpes algunos brotes críticos del Colegio Santo Tomás. Se nombró como Vicerrector a un tal doctor Alarcón, laico, experto en acallar discursos a tablazos. Los jóvenes "tomistas" manejaban los mismos textos jurídico-políticos de Santo Tomás, Vitoria, Cano, Soto, etc., que las generaciones anteriores habían conocido; pero ahora las palabras parecían adquirir nuevo sentido. Cuanto decía Tomás acerca de la ley -“ordenación de la razón para el bien común" - del gobernante -"encargado del cuidado de la comunidad"-; del mejor régimen político -mixtura de monarquía, aristocracia, democracia, en que "todos tienen parte en la soberanía" y "pertenece al pueblo la elección de los príncipes"- [...]. Cuanto decía el gran doctor contrastaba fuertemente con la realidad política que vivían los neogranadinos. 
Un conocido texto de Francisco de Vitoria, en su relección primera Sobre los indios, parecía sonar como una convocatoria a los criollos: "[...] si a algún español le nacen allí hijos y quisieran estos ser ciudadanos del país, no parece que se les pueda impedir el gozar del acomodo y derechos de los restantes ciudadanos" (Vitoria, 1960, p. 710). Esta idea preside varios textos revolucionarios de la época -como el Memorial de agravios de Camilo Torres de 1809-, y está implícita en la "defensa" de Nariño ante la Audiencia, en 1795, en la cual trata de demostrar que Santo Tomás "no sólo no se opone a las máximas" de "los derechos del hombre", "sino que las suyas son más decisivas, más claras, mucho más fuertes". Y anota que precisamente la Suma teológica, "justamente, considerada como el tesoro de la sana moral, anda en manos de la juventud" (Archivo Nariño, 1990, pp. 21-22).

Los asomos de rebelión de los "tomistas" no se dirigían sólo contra el régimen político, sino también contra ciertos hábitos académicos inveterados y contra algunas costumbres claustrales. Los jóvenes sabían muy bien que había que "poner en acto" la propia razón, considerada por Santo Tomás "participación de la luz divina en nosotros". Contra la obligación indiscutida de hablar el latín como lengua académica, "en 1791, un estudiante de la Tomística, don Pablo Plata (filósofo y canonista), se atrevió a sostener sus exámenes en castellano, causando con ello un verdadero escándalo en la república de las Letras" (Nueva historia de Colombia, 1989, p. 210). Y en 1795 los teólogos dominicos -entre ellos, el futuro coronel fray Ignacio Mariño- reclamaban contra "Ias penas de cárcel, de cepo y de azotes", abolidas en el decenio anterior, y elevaban queja firmada ante Roma.

Los "tomistas" venían haciendo ejercicios teóricos y prácticos de crítica desacralizadora y estaban más o menos sensibilizados como para plantear sin reato la posibilidad de la desobediencia política y aun del "tiranicidio". Sobre la muerte al tirano, e invocando la autoridad de Santo Tomás, ya existía el antecedente del dominico francés frere Jacques Clement, quien, en 1589, había dado muerte a Enrique III, condenado públicamente como tirano y traidor al pueblo francés. Según el historiador Groot (Groot, 1953, p. 130), la "doctrina del tiranicidio" era una doctrina liberal más atribuible a los dominicos y tomistas que a los jesuitas. De ahí que los jóvenes "monarcómacos" de la Tomística o del Rosario no tuvieran reparo en debatir de nuevo el tema, a pesar de que desde 1768 debían jurar al graduarse "no defender, ni aun con título de probabilidad, la irreligiosa, sangrienta y horrorosa máxima del regicidio y tiranicidio" (Groot, 1953 p. 130).

\section{PAPEL DE LA UNIVERSIDAD SANTO TOMÁS A PARTIR DE 1810}

Las dificultades de la Tomística, durante más de cuarenta años, con los sucesivos gobiernos virreinales habían hecho que sus alumnos, jóvenes profesores y directivos percibieran las instituciones políticas coloniales como despóticas. Ya lo había afirmado en 1781 el pro comunero hermano Archila, al denunciar las arbitrariedades de Moreno y Escandón. Eso explica, entre otras razones, la facilidad con que la Universidad entró al turbión revolucionario y el no poco entusiasmo batallador de muchos de sus miembros o egresados en los momentos decisivos del proceso.

En tal clima contestatario, el 20 de julio de 1810, el rector de la Pontificia y Regia Universidad, Maestro fray Mariano Garnica (Ariza, 1992, p. 1011) -futuro obispo republicano de Santafé de Antioquia- no duda en firmar el Acta de Independencia. Y ese mismo día, por la tarde, el dominico fray Pablo Lobatón -doctor en ambos derechos y catedrático de la Universidad-, después de apoyar por las calles la acción agitadora del líder José de Acevedo y Gómez, aconseja de manera apremiante al virrey Amar, de quien era confesor titular, la concesión del Cabildo abierto que solicita el pueblo. A Loba- 
tón se le consideraba "virtuoso e ilustrado". Llegó a ser Capellán del Ejército Libertador, con grado de Teniente Coronel.

Nueve días más tarde -relata el mencionado historiador Groot-, los destacados canonistas Don Camilo Torres y don Frutos Joaquín Gutiérrez visitaron la Universidad (Groot, 1953, p. 94) y, ante la asamblea de doctores, encarecieron a los catedráticos inculcar en los jóvenes estudiantes los principios liberales y el aborrecimiento a la tiranía. "Este punto dio lugar a una viva discusión que atrajo al claustro muchísima gente". El doctor Francisco Margallo Duquesne, profesor de Teología del Colegio de San Bartolomé, intervino para demostrar "cuán peligroso era insinuar la doctrina del tiranicidio, punto a donde podrían conducir los discursos de los oradores". "La reunión duró (desde las tres) hasta las seis de la tarde en que la comisión se retiró reiterando su encargo a los catedráticos con advertencia de prevenir a los jóvenes contra los abusos de esa doctrina [...]" (Mesanza, 1936, p. 93).

Entre agosto, septiembre y octubre del mismo año, el rector fray Mariano Garnica entregó tres diplomas al joven estudiante tomasino Atanasio Girardot, futuro héroe del Bárbula. En el Boletín de Historia de Bogotá se lee: "Atanasio Girardot entró al Colegio de Santo Tomás y allí hizo estudios de abogado hasta recibir el correspondiente diploma" (Mesanza, 1936, p. 93). En una biografía publicada en la Revista del Colegio de Nuestra Señora del Rosario se dice: "Siguió en la escuela de Derecho o sea en el Colegio de Santo Tomás de Aquino, de la ciudad de Santafé, de las Indias Occidentales" (Mesanza, 1936, p. 93).

De 1811 a 1813, varios dominicos, profesores o ex alumnos de la Tomística, de opción preferentemente federalista, actuaron como diputados de colegios electorales o como constituyentes de las nuevas repúblicas de provincia: Cundinamarca, Tunja, Cartagena, etc. El maestro Juan Antonio de Buenaventura (Ariza, 1992, p. 1013), rector de la Tomística por tres períodos, ordenó quitar de la Universidad el Escudo Real, firmó las Actas de Independencia de Cundinamarca de 1811 y 1813, y apoyó la impresión en Santafé de la denuncia de fray Bartolomé de Las Casas: "Brevísima relación de la destrucción de las Indias". En 1816 huyó a los Llanos a reunirse con varios dominicos guerrilleros. El maestro fray Juan Antonio era sobrino del doctor fray Jacinto Antonio de Buenaventura, el procurador que había defendido a la Universidad contra el plan de supresión del fiscal Moreno y Escandón.

En junio de 1819, el ex alumno tomasino, experto en cánones, fray Ignacio Mariño (Tisnés, 1963, p. $13 \mathrm{ss}$ ), en calidad de Capellán General del Ejército Libertador con grado de Coronel, arengó en el Llano de San Miguel a la cúpula patriota para convencerla de la conveniencia de remontar los Andes y marchar por Pisba hacia Boyacá en vez de hacerlo hacia Venezuela. Mariño había sido misionero y cura de Tame, en Casanare, donde organizó guerrillas en 1812, pues imaginaba que podría sobrevenir una reacción implacable por parte de los ejércitos realistas. En 1813 firmó el Acta de Independencia Absoluta de Tunja. En 1814 recibió el grado de Coronel de la Nueva Granada en calidad de Comandante del "Ejército de la Niebla", compuesto de 600 hombres, con los cuales apoyó a Bolívar en el sitio a Santafé de Bogotá, para obligarla a adherir a la Confederación de las Provincias Unidas.

El "Ejército de la Niebla" constituyó la base del Ejército comandado por el general Francisco de Paula Santander en la campaña de 1819. El belicoso fray Ignacio fue uno de los tácticos del Pantano de Vargas, territorio conocido por él, ya que era propiedad de su hermano Francisco Mariño y Soler. Fray Ignacio fue amigo incondicional y hombre de confianza de Bolívar y de Santander. Por eso, reunió los cargos de "Jefe militar de Casanare", "Jefe militar de Sogamoso", "Jefe civil de Casanare", "Prefecto civil de Sogamoso", Cura de 
Guateque y de Nemocón. Fray Ignacio reunía los títulos de "Magister missionis", "Juez eclesiástico", "Misionero apostólico del Casanare", "Caballero de la Orden de los Libertadores de Venezuela y Cundinamarca".

El 9 de septiembre de 1819, el ex rector maestro fray Mariano Garnica firmó el Acta de la Junta de la Capital, encargada de agasajar a los héroes de Boyacá y perpetuar la memoria de "la inmortal jornada". Finalizando el año, y pasada la euforia por el triunfo, el general Santander elevó consulta, a través del ex rector, al claustro de la Universidad acerca de "si la Presidencia hereda el Patronato Real". Sobre el mismo tema se había consultado varias veces a la Tomística desde 1813 y la respuesta había sido siempre negativa.

De 1820 a 1825, el claustro del Colegio-Universidad asumió abiertamente el proceso revolucionario. Sus aulas se convirtieron en escenario adecuado para agitar nuevas ideas y debatir los proyectos políticos de los próceres. Los dominicos empezaron a ser calificados de "despreocupados", que era tanto como llamarlos "ilustrados". Según Groot, quienes no eran "despreocupados", eran "fanáticos", "ignorantes" o "godos" (Groot, 1953, pp. 185, 297).

\section{APERTURA A LA MASONERÍA Y AL BIBLISMO PROTESTANTE}

El "despreocupado" claustro de la Tomística -especialmente por influencia del coronel Mariño y de connotados catedráticos- posibilitó al general Santander tener allí reuniones de la primera Logia Masónica de Santafé, ceñida a los fines filantrópicos del caballero Michel Ramsey -reformador escocés de la masonería francesa-: "un establecimiento cuyo único fin es la reunión de los espíritus y de los corazones para hacerlos mejores, y formar en la sucesión de los tiempos una nación espiritual en la que, sin derogar los diversos deberes que exige la deficiencia de los Estados, se creará un pueblo nuevo que, participando de varias naturalezas, las cimentará todas en cierto modo, por los lazos de la virtud y de la ciencia". Este fue el modelo masónico que se exportó a las colonias españolas y que fue acogido tardíamente por el general Santander y los "tomistas" santanderistas, en especial Mariño, el rector fray Joaquín Gálvez y el secretario de la Universidad, fray Antonio María Gutiérrez.

En la Gaceta Oficial de enero de 1820 apareció el siguiente aviso que no delataba las intenciones de la primera logia santafereña: “Una sociedad amante de la Ilustración, protegida por el señor general Santander, ofrece al público lecciones para aprender a traducir y hablar los idiomas francés e inglés". Tales lecciones se dictarían en la Universidad Santo Tomás. Dentro y fuera de ésta se debatió ardorosamente la verdadera naturaleza de la logia y la licitud de incorporarse a ella. El doctor fray Antonio María Gutiérrez, teólogo, canonista y elocuente orador, en el recinto del Templo de Santo Domingo, hizo pública defensa de la masonería y discutió la validez de las censuras pontificias.

La "despreocupación" de los "tomistas" no sólo se abrió a los ideales masónicos, sino que posibilitó la coexistencia de inquietudes aparentemente opuestas: por una parte, el estudio de la Ilustración francesa; por otra, la actitud ecuménica, que aproximó la cátedra de Sagrada Escritura al biblismo protestante inglés. Si desde 1820 el catedrático doctor fray Antonio María Gutiérrez hacía gala de su versación en los ilustrados materialistas -especialmente en el barón Paul Henri de Holbach (1723-1789), el mecenas de los "enciclopedistas", y en Claude Adrien Helvecio (1715-1771)-, en marzo de 1825, la Universidad se convirtió en sede oficial de la Sociedad Bíblica de Colombia, filial de la Sociedad Bíblica de Londres, favorecida también por el gobierno y con la cooperación de las autoridades eclesiásticas. 


\section{LA UNIVERSIDAD SANTO TOMÁS DESPLAZADA POR LA UNIVERSIDAD CENTRAL}

Esa "despreocupación" más o menos compartida por el claustro de la Tomística favoreció las relaciones con el nuevo Gobierno republicano, que se consideraba sucesor del Patronato real sobre la Institución. Esta seguía siendo Pontificia, pero había dejado de ser real para convenirse en republicana. En calidad de patronos, Bolívar y Santander asistían a los actos públicos más importantes. Consta que en 1820 el primero presidió la fiesta de Santo Tomás, y que en 1821 lo hizo Santander. Las buenas relaciones fueron facilitando la utilización del inmueble universitario como sede del Ejecutivo o del Legislativo. En 1823 sesionó allí el primer Congreso Constitucional de Colombia, previsto por la Constitución de Cúcuta de 1821.

Pero a pesar de que el general Santander, bachiller en filosofía por la Tomística en 1808, actuaba como patrono y presidía sesiones de graduación y aun la fiesta de Santo Tomás; a pesar de su amistad con el rector Joaquín Gálvez y con algunos catedráticos; a pesar del santanderismo casi institucional; a pesar de todo, el general Santander firmó el Reglamento de Estudios para Colombia que, el 3 de octubre de 1826, dejó sin competencia a la Tomística como Universidad de la República. La nueva Universidad Central de Bogotá (establecida en las instalaciones del Colegio de San Bartolomé) la desplazó y la redujo a Colegio de estudios primarios y preuniversitarios autorizados, con educación superior puramente conventual, aunque con posibilidad de homologar sus cursos para obtener títulos en la Central, luego de estricto control de calidad.

Pudo influir en la decisión santanderista el hecho de que el Claustro de la Tomística no había sido del todo favorable a las innovaciones curriculares republicanas y había reiterado su negativa ante la consulta acerca de si el Patronato Real se trasladaba a la República. La Universidad Central pasó a cumplir el papel de central de grados, con poderes de coordinación y control del sistema educativo, todo lo que había cumplido la Tomística durante 60 años, desde la supresión de la Javeriana en 1767. Sin título de Universidad, el Colegio Santo Tomás quedó obligado a cumplir regulaciones de la Central y a asistir a todas sus ceremonias académicas.

Escribe Groot:

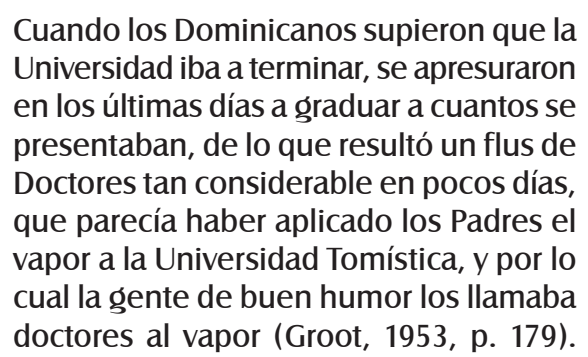

Aun cuando Groot dice que por perder el derecho a graduar "se originaron cuestiones con el rector", parece que el doctor Gálvez no favoreció la protesta y se mantuvo leal al Gobierno. Tal vez por esta lealtad, años más tarde, Santander impondrá como provincial de los dominicos al rector colaboracionista.

Si el doctor Florentino González -futuro secretario de Hacienda de Mosquera- no se apresura a graduarse el año anterior (1825), al crearse la Universidad Central habría tenido que aplazar la recepción de su título de abogado. Él mismo narra en sus memorias:
Yo asistía a todas las tres clases de de- recho en el Colegio de San Bartolomé, y además a la de derecho público del Colegio de Nuestra Señora del Rosa- rio, y a la de derecho canónico del de Santo Tomás en el convento de Santo Domingo, que era entonces la Univer- sidad. Esto me proporcionó el Ilenar pronto las formalidades escolares y ter- minar mi carrera (González, 1975, p. 86).

Coetáneo del doctor Florentino González era don Mariano Ospina Rodríguez; pero éste no terminó estudios a tiempo y debió irse a terminarlos al Estudio Dominicano de Tunja, donde se graduó 
de abogado en 1827. Allí fue condiscípulo de fray Bernabé Rojas, futuro Provincial de los dominicos y Obispo de Santa Marta. Conjurado de la noche septembrina de 1828, Mariano Ospina mantuvo contacto secreto con algunos profesores y frailes santanderistas del Colegio Santo Tomás, que protegieron al cabecilla de la conjuración, el capitán Pedro Carujo, ex alumno de matemáticas e idiomas del mismo Colegio.

\section{LAS FILIALES DE LA TOMÍSTICA}

Puesto que resulta insólita la actuación del Estudio tunjano al graduar a Mariano Ospina Rodríguez, se impone un excursus acerca de las filiales de la Tomística. El Estudio Dominicano de Tunja se organizó por lo menos diez años antes que el de Santafé de Bogotá -origen remoto de la Tomística-. En 1608 fue convertido en Universidad de Estudio General y funcionó como filial del ColegioUniversidad de Santo Tomás, que escogía sus catedráticos y otorgaba grados a sus estudiantes. Parece que, a veces, el Estudio tunjano era autorizado por la Tomística para expedir títulos, posteriormente refrendados por ésta. Algo semejante ocurría con el Estudio Dominicano de Cartagena, convertido en Estudio General en 1644. De ahí que allí pudiera graduarse en leyes, en 1802, don José María del Castillo y Rada. En situación análoga a la de los estudios mencionados estaba el Estudio Dominicano de Santa Marta, inaugurado en 1673 por el obispo historiador don Lucas Fernández de Piedrahíta; y el Estudio de Popayán, donde se fundó, con participación dominicana, la Universidad del Cauca en 1827. Entre 1803 y 1806, el rey afilió, en condiciones equiparables a las de los estudios, y para graduar en teología, cánones y leyes, el Colegio de Mérida de Maracaibo y el Seminario de Caracas.

Llama la atención que, cuando la Tomística quedó reducida a Colegio y sin valor público sus estudios superiores, el Ministerio del Interior concedió valor universitario a los cursos de teología del Estudio de
Tunja, apto para "obtener grados en la Universidad Central". Esta era una exigencia de los vecinos de Tunja y petición expresa del rector del Colegio de Boyacá, quien solicitaba igual concesión para las cátedras de teología de los franciscanos.

\section{VOLUNTAD DE PERSISTENCIA DE LA UNIVERSIDAD TOMÍSTICA}

Al dejar Santander a la Tomística sin competencia universitaria pública, no hubo resistencia, entre otras razones, porque los dominicos estaban divididos en dos "partidos": uno muy cercano al Gobierno, conformado por frailes ilustrados conscientes de que había que abandonar los planes de estudios heredados de la Colonia; el otro, más preocupado por mantener la tradición, dentro de las consignas venidas de Roma. Ese conflicto no permitió organizar oposición unitaria.

Pero la Institución no desapareció y continuó con su estructura, sus costumbres, sus estatutos y sus tres niveles formativos, renovando aceleradamente Ios planes de estudio, por lo cual logró sobresalir entre los colegios mayores. Especialmente, a partir de 1834, cuando el inmueble recibió mejoras locativas y sus aulas fueron readecuadas y dotadas (Plata, 2005, p. 355).

El Colegio Santo Tomás, aunque despojado de sus atribuciones para otorgar títulos profesionales, al contar con tradición y experiencia educativas centenarias, amén de recursos económicos y didácticos, no necesitaba esforzarse mucho para emular las nuevas instituciones santanderistas, que no podían sobresalir por haber nacido débiles académica y económicamente. La Universidad Central pretendió incautar los bienes del Colegio Santo Tomás, pero los frailes ganaron el pleito. Más tarde, el gobierno de la Provincia de Cundinamarca quiso oficializar el Colegio, pero también perdió el pleito.

Libre de acosos, el Colegio fue adquiriendo mayor prestigio, no sólo por sus programas de educación superior, sino como institución de secundaria y de 
primaria. Así, 27 años después de haber perdido su condición universitaria ancestral, en 1853, "EI catolicismo" reconocía:

\begin{abstract}
Este establecimiento sostenido por el ilustrado patriotismo de los religiosos de Santo Domingo [...] es uno de los pocos planteles de educación que han quedado en la capital de la República, después de la destrucción completa de este ramo, hecha por la nueva democracia. Allí han encontrado un recurso los padres de familia para la educación secundaria de sus hijos, y los pobres tienen también allí una escuela de primeras letras.
\end{abstract}

El mismo periódico arquidiocesano reconocía, dado el lucimiento de los actos académicos de los tomasinos, la calidad de sus profesores y de sus estudiantes, que evidenciaban alta instrucción en latín, francés, español, matemáticas, geografía, retórica, filosofía, teología y derecho.

En procura de la excelencia y del reconocimiento público, el Colegio Santo Tomás se preparó para recuperar su condición de Universidad Pontificia en 1855, aprovechando la ley de José Hilario López, de 1850 (ICFES, 1974, pp. 563-565), que consagraba la libertad de enseñanza, suprimía el título de bachiller, autorizaba a los colegios y seminarios a expedir títulos profesionales, y suprimía las universidades oficiales. Sin duda, cumpliendo las previsiones de la Ley de López, el Colegio Santo Tomás pudo esporádicamente expedir títulos en filosofía, teología o derecho canónico.

\section{"APROVECHA LA HISTORIA, CONSTRUYE FUTURO"}

Con este eslogan de las "Jornadas Universitarias Tomasinas" de 2010 se traduce el postulado del Aquinate: "Del pasado recordado y del presente comprendido, extraemos la previsión del futuro" $(\mathrm{ST}, \mathrm{I}, 22,1)$. Maurice Claudel afirmaba que "el futuro no se prevé, sino que se construye"; pero de acuerdo con el eslogan y la afirmación tomasiana, la construcción prospectiva no puede partir de cero, desde la voluntad imaginativa, pues se rompería la continuidad tritemporal del devenir: el pretérito condiciona el presente y éste, preñado de las experiencias recibidas y de las realizaciones actuales, asegura la construcción realista del porvenir.

"Aprovechar la historia" consiste en descubrir las claves de la memoria para convertirlas en lente de aproximación a la sucesión factual a fin de desvelar las tendencias contemporáneas, sin las cuales toda previsualización prospectiva se torna fantasiosa, utópica, en el sentido de negadora de posibilidades de realización espacio-temporal. Sin duda que interesa la "utopía", pero en el sentido de "eu-topía", como proyecto optimista que prolonga las fortalezas y oportunidades del presente.

Esta breve historiovisión en torno al papel cumplido por la Universidad Santo Tomás en la gesta independentista, desde los esbozos ideológicos precursores hasta la supresión de 1826 en beneficio de la Universidad Central santanderista, y luego su gradual recuperación y fortalecimiento académico hasta la restauración de 1855, tiene por objetivo discernir, con ocasión de la conmemoración del Bicentenario de la Independencia, qué lecciones podemos recibir aún de nuestra memoria institucional.

Si nos atenemos a las peripecias centrales conservadas por esa memoria, descubrimos que la Universidad Tomística no podía quedar marginada, como si su presencia en la sociedad neogranadina hubiera sido anodina, y que la historia nacional no puede soslayar su papel en la formación de nuestra identidad nacional.

Al pretender continuar "construyendo futuro" para nuestra Universidad Santo Tomás del siglo XXI, sin duda que no podemos asumir todo el pasado, como si hubiera univocidad fijista entre la entidad de ayer y la entidad de hoy, como si la nueva Tomística restaurada en 1965 fuese mera continuidad estacionaria de la institución colonial 
y republicana, la cual fungió por décadas como la única universidad de la Nueva Granada, centro de atención y punto de referencia de las demás instituciones, tanto educativas como políticas y religiosas.

La Universidad Santo Tomás del siglo XX, aunque hace efectivo el restablecimiento jurídico de la antigua Tomística, ya no es la única universidad del país, ni es monárquica, ni pontificia, ni debe asegurar corrección ideológica al servicio de un imperio, ni coordina ni controla a las demás instituciones educativas, ni es el centro de atención de la Iglesia y del Estado, ni debe controlar la "pureza de sangre", ni la filiación legítima de los graduandos, que debían ser exclusivamente varones, ni impone el latín como lengua académica, ni tiene entre sus opciones el chibcha, ni los graduandos deben pasear a caballo por las principales calles de Santafé con música y pendones. La nueva Tomística no tiene que intervenir directamente en procesos tan riesgosos como el de la Independencia, ni ofrecer sus inmuebles al gobierno, ni pugnar por subsistir, afirmando su identidad originaria, dentro de un sistema educativo que tendía a excluirla.

Pero, en general, a pesar de que la misión de la antigua y de la hodierna Tomísticas ha debido adaptarse de distinta manera a las exigencias y posibilidades de sus propios tiempos, podemos derivar de la historia que las une, en legítimo relevo, por vía analógica, algunos principios que nos pueden servir de pautas firmes para continuar "construyendo futuro". "Construir futuro" no es un mero eslogan publicitario, sino impulso natural de toda institución que considera vigente su misión y necesaria hoy para cooperar en la gestación del futuro incluyente e integrador de la sociedad colombiano-continental y de la humanidad a las que sirve.

Enunciemos, como conclusión, las pistas metódicas que la historiovisión anterior nos proporciona y que nos pueden servir para la necesaria prospec- ción de lo que hay que ir construyendo a fin de asegurar la permanencia de la USTA:

1. Mantener la fidelidad al realismo tomista, el cual exige comprender el humanismo cristiano a partir de los interrogantes de los hombres y de las expectativas que sugieren los signos de los tiempos, a fin de ir suministrando a la sociedad itinerarios con sentido.

2. Afirmar la identidad nacional en el contexto de la gran patria continental.

3. Mantener actuante el paradigma liberador de la misión dominicana, que reclama siempre la igualdad del género humano.

4. Hacer valer de manera constante la ética de los derechos humanos en la perspectiva del humanismo cristiano tomista.

5. Promover la resistencia a toda forma de tiranía o de opresión, optando primordialmente por los más débiles.

6. Rechazar toda discriminación y afirmar nuestras "impurezas" culturales y nuestros creativos mestizajes.

7. Propiciar la apertura dialogal a otras manifestaciones culturales o ideológicas.

8. Afirmar la identidad institucional, adaptándose a las exigencias de los cambios necesarios y buscando la excelencia.

9. Afirmar la autonomía de la Universidad como independencia en la búsqueda de la verdad.

10. Favorecer y promover la participación igualitaria de la mujer, cuya originalidad y capacidad de liderazgo puede rescatar a los varones cuando el miedo o la resignación los acostumbra a "no sentir sus enjalmas", como decía fray Archila en la "Cédula del Común" de 1781. 


\section{REFERENCIAS}

Ariza, O.P., fray Alberto, (1971). Fray Ciriaco de Archila y Fray José Simón de Archila, Biografías. Bogotá: Kelly.

Ariza, O.P., fray Alberto, (1992). Los dominicos en Colombia, vol. II. Bogotá: Anthropos.

Anónimo (s.f.). Memoria Justificativa de Sentimientos del Angélico Doctor Santo Tomás sobre la absoluta independencia de los Soberanos, sobre la indisolubilidad del juramento de sus vasallos, y sobre el Regicidio. Manuscrito de mediados del siglo XVIII, Archivo de la Provincia Dominicana de Colombia.

Archivo Nariño (1990). Biblioteca Presidencia de la República. Bogotá.

Archivo de Provincia (s.f.). Convento San Alberto Magno. Diplomas Universidad Tomística.

Cabrejo, O.P., fray Antonio (s.f.). Tractatus De lure et lustitia, manuscrito. Archivo de la Provincia Dominicana de Colombia.

Cárdenas, A. (s.f.). Historia del primar claustro universitario de Colombia. En Realidad, 4. Bucaramanga.

De Buenaventura, O.P., fray Jacinto (1984). Tractatus de Actibus Humanis, Bogotá: USTA.

González, F, (1975). Memorias. Medellín: Bedout.

Groot, J. (1953). Historia eclesiástica y civil de la Nueva Granada. Bogotá: ABC.
ICFES (1974). Compilación de normas sobre la educación superior. En: La República Neogranadina, vol. II, part. II, Bogotá.

Nariño, A. (1823). Los toros de Fucha, tercera corrida.

Nueva Historia de Colombia, vol. I, (1989). Bogotá: Planeta.

Mesanza, O.P., Andrés. (1936). Apuntes y documentos sobre la Orden Dominicana en Colombia. Caracas: Suramérica.

Molina, E. (1984). 800 titulados en filosofía entre 1768-1808. En: Cuadernos de Filosofía Latinoamericana, 21. Bogotá.

Parra, C. (1980). Prólogo. Historia de la Provincia de San Antonino del Nuevo Reyno de Granada, fray Alonso de Zamora. Bogotá: Kelly.

Plata, W, (2005). La Universidad Santo Tomás de Colombia ante su historia. Bogotá: USTA.

Tisnés, R. (1971). Historia extensa de Colombia, Vol. XIII, t. 4. Bogotá: Lerner.

Tisnés, R. (1963). Fray Ignacio Mariño, O.P., CapeIlán General del Ejército Libertador. Bogotá: ABC.

Vitoria, O.P., Francisco (1960). Obras. Madrid: BAC.

Zamora, O.P., Alonso (1980). Historia de la provincia de San Antonino del Nuevo Reyno de Granada, t. I. Bogotá: Kelly. 